\title{
HYPERICUM PERFORATUM L. HAIRY ROOT EXTRACTS - REGULATION OF GLYCEMIC, METABOLIC, SERUM ENZYME AND LIPID PROFILE IN STZ - INDUCED DIABETIC RATS
}

\author{
Elena Rafailovska1, Oliver Tushevski², Sonja Gadzovska - Simic ${ }^{2}$, \\ Suzana Dinevska - Kjovkarovska ${ }^{1}$, Biljana Miova ${ }^{1}$ \\ ${ }^{1}$ Department of Experimental Physiology and Biochemistry, Institute of Biology, \\ Faculty of Natural Sciences and Mathematics, Ss Cyril and Methodius University, \\ 1000 Skopje, North Macedonia \\ ${ }^{2}$ Laboratory of Plant Cell and Tissue Culture, Institute of Biology, \\ Faculty of Natural Sciences and Mathematics, Ss Cyril and Methodius University, \\ 1000 Skopje, North Macedonia
}

Received 30 August 2021; Received in revised form 28 September 2021; Accepted 8 October 2021

\begin{abstract}
Apart from currently available therapeutics for the treatment of diabetes mellitus, much attention has been paid to discover phytochemicals from natural resources, mainly due to their low side-effects. Hypericum perforatum hairy root (HR) transformed with Agrobacterium rhizogenes A4 represent prospective experimental system enriched in xanthones, known as potent antidiabetic agents. Thus, the aim of this study was to evaluate HR extracts for their potential antihyperglycemic activity in streptozotocin (STZ)-induced diabetic rats, also compared to the effects of wild-growing Hyperici herba (HH). We conducted an acute-toxicity study, multiple dose study, and $24 \mathrm{~h}$ blood glucose measurements after a single dose administration of $\mathrm{HH}$ and $\mathrm{HR}(200 \mathrm{mg} / \mathrm{kg})$ in diabetic rats. Furthermore, we examined the effects of 14-days administration of $\mathrm{HH}$ and HR extracts on blood glucose levels, metabolic parameters, enzyme, and lipid status in healthy and diabetic rats. Both extracts produced a fall of about $70 \%$ in blood glucose level after $24 \mathrm{~h}$ of administration. Two-week treatment with $\mathrm{HH}$ and HR induced a significant decrease (70-72\%) in blood glucose levels. Moreover, we found an improvement of the dysregulated metabolic parameters (body weight, food, and water consumption and urine output). Serum enzyme (AST, ALT, and $\gamma-\mathrm{GT}$ ) and lipid profile parameters (CHOL, TAG, and HDL) were also improved by both extracts. These findings might provide a new insight for managing diabetic hyperglycemia and dysregulated serum enzyme and lipid profile, using extracts from transgenic roots cultures from $H$. perforatum.
\end{abstract}

Key words: hairy roots, hanthones, STZ-diabetic rats, Hypericum perforatum L., antihyperglycemic

\section{INTRODUCTION}

Although different hypoglycemic drugs have been synthesized for the treatment of diabetes mellitus, many synthetic drugs have a number of serious side effects (1). The management of hyperglycemia with minimal side effects and low

Corresponding author: Prof. Biljana Miova, $\mathrm{PhD}$

E-mail address: bmiova@pmf.ukim.mk

Present address: Department of Experimental Physiology and Biochemistry, Institute of Biology, Faculty of Natural Sciences and Mathematics, Ss Cyril and Methodius University, 1000 Skopje, North Macedonia Phone:+ 38923249604

Copyright: (C) 2021 Rafailovska E. This is an open-access article published under the terms of the Creative Commons Attribution License which permits unrestricted use, distribution, and reproduction in any medium, provided the original author and source are credited. Competing Interests: The authors have declared that no competing interests exist.

Available Online First: 23 November 2021

Published on: 15 March 2022

https://doi.org/10.2478/macvetrev-2021-0027 costs is still a challenge to the medical system (2). Comparatively low side-effects and low-cost phytochemicals from natural resources open new avenues for the treatment of various diseases including diabetes (3).

Hypericum perforatum L. represents one of the best studied medicinal plants throughout the world with well-characterized bioactive metabolites and pharmacological properties $(4,5)$. Consequently, $H$. perforatum based products are prepared from Hyperici herba $(\mathrm{HH})$ crude material as a source of natural bioactive pharmaceuticals. The H. perforatum extracts contain naphthodianthrones, flavonol glycosides, biflavonoids, phloroglucinol derivatives, and xanthones (4) that are responsible for antidepressant, anti-inflammatory, antiviral, anticancer, antibacterial, and antidiabetic activities (6). 
Among these bioactive compounds, xanthones are known as the most potent antidiabetic agents $(7,8$, $9,10,11)$.

In the last decade, $H$. perforatum extracts were found to have antihyperglycemic and antidiabetic activity in different animal models of diabetes (12, $13,14,15)$. Still, the contribution of xanthones to the antidiabetic activity of $H$. perforatum has not been considered due to the apprehension that this class of compounds is mainly accumulated in the roots and only trace amounts have been found in the field-grown plants and commercially available products (16).

In the search of alternatives for sustainable production of bioactive compounds, Agrobacterium rhizogenes - mediated transformation of $H$. perforatum represents an effective biotechnological approach for increasing production of existing secondary metabolites, as well as for biosynthesis of new bioactive components (17). In that sense, genetic transformation of $H$. perforatum with Agrobacterium rhizogenes (A4 and A4M70GUS) leads to the establishment of $H$. perforatum hairy root (HR) cultures that accumulated significant quantities of various xanthones $(18,19)$.

Even though in vitro antioxidant and radicalscavenging properties of $H$. perforatum $\mathrm{HR}$ extracts have already been reported (17), the antidiabetic activity of those cultures has never been explored. Thus, the abundance of various xanthones in $H$. perforatum HR cultures could make them potential candidates for evaluation of their yet unknown in vivo antidiabetic property in streptozotocin (STZ)-induced diabetic rats.

To the best knowledge of the authors, this was the first conducted study of the antihyperglycemic properties of xanthone-rich HR extracts. The aim of the study was to compare the effects of $\mathrm{HH}$ and the xanthone-rich HR extract by conveying basic toxicity test, blood glucose regulation assessment during single and multiple dose treatments, basic metabolic parameters regulation assessment (body weight, food consumption, water uptake, and urine output), hepatic damage key enzyme markers assessment (AST, ALT and $\gamma$-GT), and serum lipid profile assessment (CHOL, TAG and HDL).

\section{MATERIAL AND METHODS}

\section{Plant material}

Seeds from $H$. perforatum wild-growing plants (voucher number 060231), collected from a natural population in the Republic of North
Macedonia, were used for the establishment of in vitro grown seedlings. The experimental protocols for Agrobacterium rhizogenes A4 transformation of $H$. perforatum and induction of HR cultures were described in the study of Tusevski et al. (18).

\section{Preparation of extracts}

One-month-old $H$. perforatum HR (cultured in liquid $\mathrm{MS} / \mathrm{B}_{5}$ medium) were collected and lyophilized to absolutely dried state. The extraction of phenolic compounds from lyophilized plant material $(0.2 \mathrm{~g})$ was performed in the presence of $80 \%(\mathrm{v} / \mathrm{v}) \mathrm{CH}_{3} \mathrm{OH}$ by using ultrasonic bath for 15 minutes (20). The methanolic extracts were then centrifuged at $15000 \mathrm{~g}$ for 15 minutes, and the resulting supernatants were evaporated to dryness under vacuum (50 mbar) at room temperature using rotary evaporator system. The dried extracts were dissolved in $0.3 \%$ carboxymethylcellulose-CMC (w/v in distilled water) at a concentration of $20 \mathrm{mg} / \mathrm{mL}$. The identification and quantification of phenolic compounds in HR and HH methanolic extracts was previously performed using highperformance liquid chromatography (HPLC), coupled with diode-array detection (DAD) and tandem mass spectrometry (MSn) with electrospray ionization (18).

\section{Animals}

Healthy adult Wistar rats (weighted 200-250 g, aged 14-16 weeks) obtained from the Vivarium of the Faculty of Natural Sciences and Mathematics, Skopje, were kept under standard environmental conditions. All experiments were performed in accordance with the current ethical norms approved by the Animal Ethics Committee of the University "Ss. Cyril and Methodius", Skopje, R. North Macedonia (03-2323/2), following the International Guiding Principles for Biomedical Research Involving Animals, as issued by the Council for the International Organizations of Medical Sciences. The anesthetic-sodium thiopental $(45 \mathrm{mg} / \mathrm{kg}$ body weight) was applied according to the standards given by the guide of the EC Directive 86/609/EEC and 2010/63/EU.

\section{Acute toxicity study}

The acute oral toxicity study was performed on healthy Wistar rats of both sexes, according to the Organization for Economic Co-operation and Development (OECD) Guideline no. 423. Group 1 (control group, $n=6$ ) received only vehicle, while Group $2(n=6)$ received multiple doses of $\mathrm{HR}$ 
extracts $(500,1500,2000 \mathrm{mg} / \mathrm{kg})$. Following the extract administration (via feeding needle), the animals were observed for three hours for any changes in the autonomics, general behavioral, and neurological profiles. The observations were continued for the subsequent $24 \mathrm{~h}$ in three-hour intervals for mortality, and daily for 14 days.

\section{Experimental design}

Experimental diabetes was induced by single intraperitoneal injection freshly dissolved STZ, (Sigma Aldrich, Bangalore) $(45 \mathrm{mg} / \mathrm{kg})$ in cold citrate buffer ( $\mathrm{pH} 4.5,0.1 \mathrm{M})$. Diabetic rats were confirmed three days after the STZ injection. After seven days of STZ administration, rats with fasting blood glucose above $15 \mathrm{mmol} / \mathrm{L}$ were considered diabetic and were included in the study. The hypoglycemic drug glibenclamide (Glb) $(2.5 \mathrm{mg} / \mathrm{kg})$ was used as a positive control during the study. All treatments were administered through oral route via feeding needle.

\section{Dose-dependent study}

Dose dependent study was performed to evaluate the effects of different doses of the $\mathrm{HH}$ and HR extract on blood glucose levels in diabetic rats. The diabetic rats were randomly divided into seven groups $(n=6)$, fasted overnight, and administered $0.3 \% \mathrm{CMC}(\mathrm{D}), \mathrm{HH}(\mathrm{DH})$, and HR (DHR) extracts $(100,200$, and $300 \mathrm{mg} / \mathrm{kg})$. Blood glucose level was measured using glucometer in blood samples collected from tail prior to extract administration as well as 8 hours after.

\section{Single-dose study}

In this experiment, the regulation of glycemia with single application of $\mathrm{HH}$ and $\mathrm{HR}$ extracts in diabetic rats was monitored. The rats were randomly assigned into 5 groups of six animals each. I. Normal control rats (C) - placebo treated with water. II. Diabetic control rats (D) - placebo treated with $0.3 \%$ CMC. III. Diabetic rats treated with Glb (DGlb) IV. Diabetic rats treated with H. perforatum extract (DH) $(200 \mathrm{mg} / \mathrm{kg}$ body weight); V. Diabetic rats treated with hairy roots extract (DHR) (200 mg/kg body weight). All the rats were fasted for $8 \mathrm{~h}$ prior to the treatment, but were allowed a free access to water before and throughout the experiment. Blood glucose level was measured using glucometer in blood samples collected from tail vein prior to the extract administration $(0 \mathrm{~h})$ as well as $1,2,4,6,8,12$, and $24 \mathrm{~h}$ after.

\section{Multiple-dose study}

This experimental design was employed to investigate the effect of multiple-dose treatment (14-day treatment) with $\mathrm{HH}$ and $\mathrm{HR}$ extracts in healthy and diabetic rats, comprising eight rats in each group:

C - Normal control, treated with water.

$\mathrm{CH}$ - Healthy rats treated with $\mathrm{HH}$ extract (200 mg/kg body weight)

CHR - Healthy rats treated with HR extract (200 mg/kg body weight)

D - Diabetic control treated with $0.3 \% \mathrm{CMC}$

DGlb - Diabetic rats treated with Glb $(2.5 \mathrm{mg} / \mathrm{kg}$ body weight)

$\mathrm{DH}$ - Diabetic rats treated with $\mathrm{HH}$ extract (200 mg/kg body weight)

DHR- Diabetic rats treated with HR extract (200 mg/kg body weight).

All treatments were administered once daily, in $8 \mathrm{~h}$ fasted rats (water ad libitum) which were then allowed a free access to water and food after the treatment. Fasting blood glucose (before the treatment) was measured using glucometer in blood samples collected from tail vein prior to the extract administration during the 14-day treatment.

The body weight changes and food consumption were measured during the experiment at day 1, 7 and 14. Urine output collections as well as water and food consumptions were evaluated using metabolic cages (Ugobasile, 41700, Verase, Italy) at the last day of the experiment.

Blood was collected from the dorsal vein in serum and plasma separation tubes.

\section{Biochemical analysis}

Glycemic profile was estimated trough quantification of glucose levels using GOD method, colorimetric kit (Human, Germany). Also, serum level of triglycerides (TAG), total cholesterol (TC) and high-density lipoprotein (HDL), serum glutamicoxaloacetic transaminase (SGOT/AST), serum glutamicpyruvic transaminase (SGPT/ALT) and $\gamma$-glutamyltransferase $(\gamma-\mathrm{GT})$ were evaluated using commercially enzymatic tests (Human, Germany).

\section{Statistical analysis}

All values were expressed as mean \pm SEM or SD. Statistical analysis was performed by one-way analysis of variance (ANOVA) followed by Tukey's post hoc test. The results were considered statistically significant at $\mathrm{p}<0.05$. GraphPad Prism (version 9) software was used for statistical analysis. 


\section{RESULTS}

\section{Acute toxicity study}

HR-treated animals of both sexes did not show any alterations in their neurobehavioral patterns, health status, or mortality at the highest used dose of $2000 \mathrm{mg} / \mathrm{kg}$. When compared to vehicle-treated group, there were no significant changes in the body weight and food intake. Hence, the extract was suggested to be safe for consumption even at the dosage of $2000 \mathrm{mg} / \mathrm{kg}$.

\section{Dose dependent-study}

Following the results of the acute toxicity test, different doses of both extracts $(100 \mathrm{mg} / \mathrm{kg}, 200 \mathrm{mg} / \mathrm{kg}$ and $300 \mathrm{mg} / \mathrm{kg}$ ) were used to determine their effectiveness (Table 1). The diabetic group showed non-significant reduction in blood glucose level after eight hours. A single treatment with $\mathrm{HH}$ extract (applied in three doses) led to a significant decrease in blood glucose concentration after eight hours of application $(-22.7 \%,-29.4 \%$ and $-26.9 \%$, respectively). Similarly, treatment with three doses of HR extract resulted in a significant reduction in blood glucose concentration of $-28.6 \%,-31.6 \%$ and $-21.7 \%$, respectively. However, with this experiment we found that the dry extract from $\mathrm{HR}$ shows reduced solubility in $0.3 \% \mathrm{CMC}$ at a dose of $300 \mathrm{mg} / \mathrm{kg}$. Accordingly, in the subsequent experiments, a dose of $200 \mathrm{mg} / \mathrm{kg}$ was used for both extracts.

\section{Single dose-study}

Figure 1 shows the effects of single dose treatment with $\mathrm{HH}$ and HR extracts in STZ-diabetic rats. The blood glucose level of the healthy control animals was significantly reduced by about $14.6 \%$. On the other hand, diabetic animals showed high glycemia in all measurements made in the first 12 hours (above $15 \mathrm{mmol} / \mathrm{L}$ ) which in the last measurement (24 hours) showed a decrease to $9 \mathrm{mmol} / \mathrm{L}$ (D0:D24, $-53.3 \%, \mathrm{p}<0.05$ ). The three treatments of diabetic animals (DGlb, DH and DHR) showed similar dynamics. The first decrease in the glycemia was observed after the first hour of treatment and already in the eighth hour of treatment

Table 1. Blood glucose concentration in diabetic animals depending on treatment with different doses $(100 \mathrm{mg} / \mathrm{kg}$, $200 \mathrm{mg} / \mathrm{kg}$ and $300 \mathrm{mg} / \mathrm{kg}$ ) of $\mathrm{HH}$ and HR extract

\begin{tabular}{ccccc}
\hline \multirow{2}{*}{ Treatment } & \multirow{2}{*}{$\begin{array}{c}\text { Dose } \\
\text { (mg/kg body weight) }\end{array}$} & $\mathbf{0 ~ h}$ & $\mathbf{8 h}$ & Percentage decrease \\
\cline { 3 - 4 } & $/$ & $19.5 \pm 1.2$ & $18.9 \pm 1.2$ & $-3.1 \%$ \\
\hline HH & 100 & $16.7 \pm 4.2$ & $12.9 \pm 2.5^{*}$ & $-22.7 \%$ \\
& 200 & $25.8 \pm 4.5$ & $18.2 \pm 0.7^{*}$ & $-29.4 \%$ \\
& 300 & $22.6 \pm 5.1$ & $16.5 \pm 4.5^{*}$ & $-26.9 \%$ \\
\hline HR & 100 & $19.0 \pm 2.0$ & $13.7 \pm 4.1^{*}$ & $-28.6 \%$ \\
& 200 & $22.4 \pm 2.0$ & $15.3 \pm 2.5^{*}$ & $-31.6 \%$ \\
& 300 & $22.8 \pm 4.2$ & $17.85 \pm 4.2^{*}$ & $-21.7 \%$ \\
\hline
\end{tabular}

Data are presented as mean \pm SD. Significant differences $(\mathrm{p}<0.05): *$ compared to blood glucose concentration measured at $0 \mathrm{~h}$

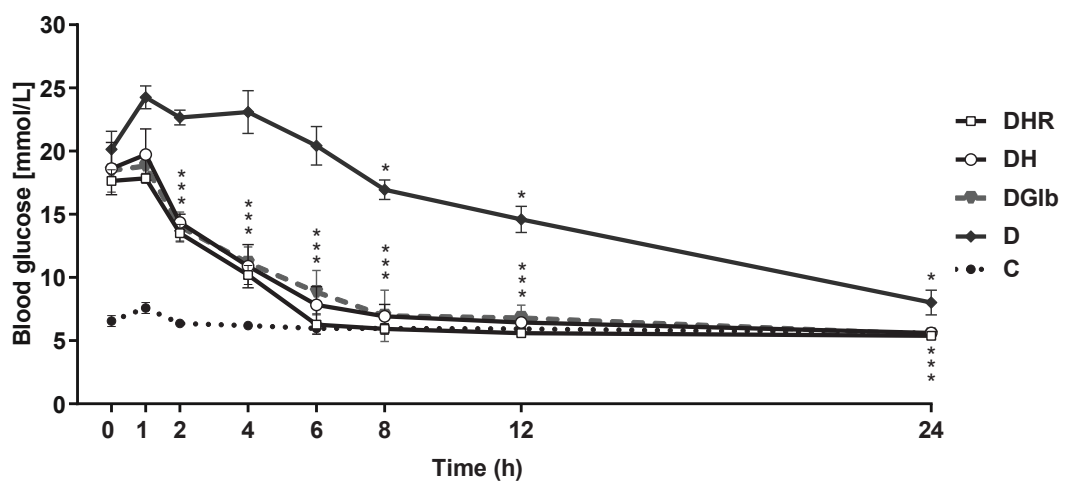

Figure 1. Changes in blood glucose levels in diabetic rats treated with single dose of Glb, HH and HR extract during 24-hour period. Data are presented as the mean \pm SD. *Significant difference $(p<0.05)$ compared to glucose measured in 0 hours 
the glucose concentration was reduced to normal values (about $7 \mathrm{mmol} / \mathrm{L}$ ). This normoglycemia was maintained until the 24th hour. Namely, at 24 hours, the measured glycemia in Glb, HH, and HR-treated animals was significantly reduced by $-68.9 \%$, $-69.5 \%$ and $-69.9 \%$, respectively, compared to the glycemia measured before the beginning of treatment $(0 \mathrm{~h})$.

\section{Multiple-dose study}

Figure 2 shows the effect of the two-week treatment with $\mathrm{HH}$ and HR extracts on the blood glucose level in healthy and STZ-diabetic rats. All control groups $(\mathrm{C}, \mathrm{CH}$, and $\mathrm{CHR}$ ) were normoglycemic (approximately $6.77 \mathrm{mmol} / \mathrm{L}$ ) throughout the experiment $(\mathrm{C} 0: \mathrm{C} 14$; $\mathrm{CH} 0: \mathrm{CH} 14$; CHR0:CHR14, n.s.).

The diabetic control group demonstrated hyperglycemia (glycemic values greater than $20 \mathrm{mmol} / \mathrm{L}$ ) during the two-week period, while the 14-day treatment of diabetic animals with Glb caused a decrease in glycemia of $31.1 \%$, which is statistically insignificant. The treatment of diabetic animals with HR extract caused a significant reduction in glycemia of about $33.5 \%$ and $35.1 \%$ on the $2^{\text {nd }}$ and $4^{\text {th }}$ day of treatment, respectively. Both $\mathrm{HH}$ and HR treatments caused a significant reduction in glycemia in diabetic animals for about $43 \%$ and $50 \%$ (for DH and DHR, respectively) on the $6^{\text {th }}$ day of treatment. At the end of the experiment (day 14), $\mathrm{HH}$ extract caused a decrease in glycemia by $70.3 \%$ $(\mathrm{p}<0.05)$, while treatment with HR extract by $71.8 \%$ $(\mathrm{p}<0.05)$.

The plasma glucose in healthy and STZ-diabetic rats treated with $\mathrm{HH}$ and $\mathrm{HR}$ extracts measured at the end of the 14-day treatment are presented on Fig. 3. Both treatments of control animals did not lead to significant changes in blood glucose concentration. The treatment of diabetic animals with Glb significantly reduced glucose concentration by $-38.5 \%$ (D:DGlb, $\mathrm{p}<0.05$ ), but still did not lead to normoglycemia (C:DGlb $\mathrm{p}<0.05)$. The treatments of diabetic animals with $\mathrm{HH}$ and $\mathrm{HR}$ extracts reduced glucose concentrations by $70.1 \%$ and $72.7 \%$, respectively (D:DH, D:DHR, $\mathrm{p}<0.05$ ), achieving normoglycaemia (C:DH, C:DHR, ns).

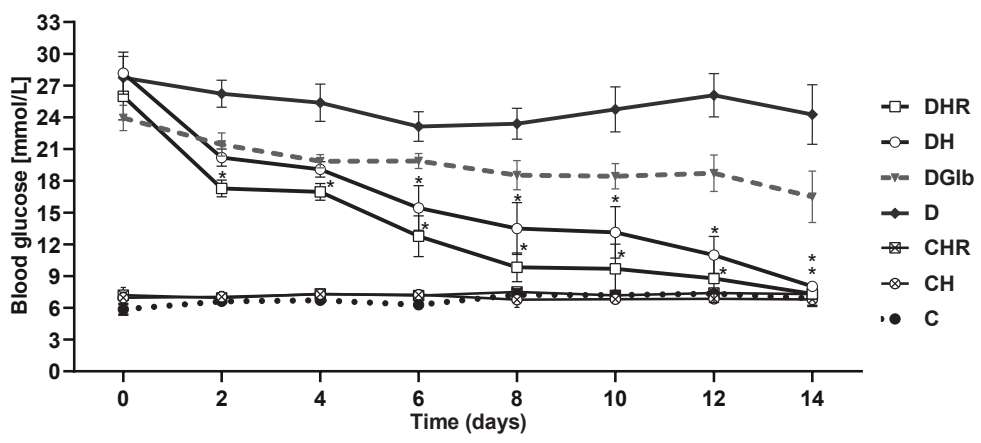

Figure 2. Changes in fasting blood glucose during two-week treatment of healthy and diabetic rats with $\mathrm{HH}$ and HR extracts. Data are presented as the mean \pm SD. ${ }^{*}$ Significant difference $(p<0.05)$ compared to blood glucose concentration measured on day 0 of the treatment

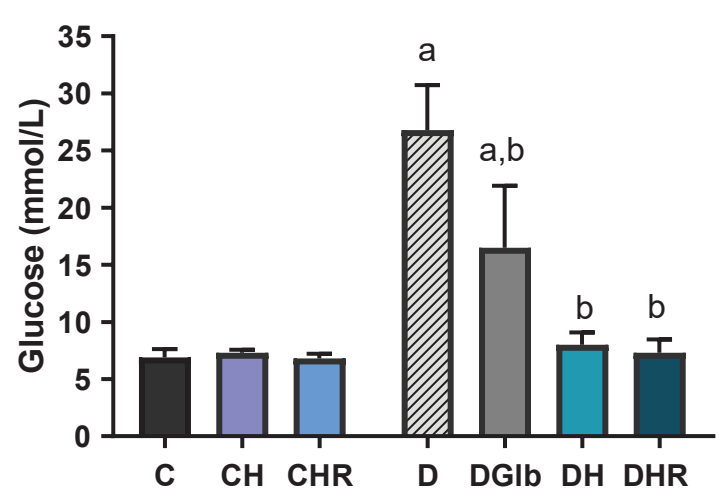

Figure 3. Changes in plasma glucose concentration in healthy and diabetic rats with $\mathrm{HH}$ and $\mathrm{HR}$ extracts. Data are presented as the mean \pm SD. ${ }^{*}$ Significant differences ( $p<0.05$ ): a-compared to $\mathrm{C}$; b-compared to D; c-compared to DH 
The effect of the two-week treatment of $\mathrm{HH}$ and HR extracts on the body weight (A) and food consumption (B) in healthy and STZ-diabetic rats are shown in Fig. 4. Namely, during the 14-day treatment, in all groups of control animals $(\mathrm{C}, \mathrm{CH}$, and CHR) there was an average increase in body weight of about $15 \%, \mathrm{p}<0.05$. The diabetic controls showed a decrease in body weight of $-29.1 \%$ (D1: D14, $\mathrm{p}<0.05$ ), while treatment with Glb caused only slight improvement and less pronounced changes in body weight of $-13.5 \%(p<0.05)$. The $\mathrm{HH}$ and HR treated diabetic animals showed no significant $(0.2 \%$ and $0.8 \%$, respectively) changes in body weight between the first and 14th day of the experiment. The food consumption was increased by $45.5-57.3 \%$ in control animals $(\mathrm{C}, \mathrm{CH}, \mathrm{CHR})$ while in the diabetic group the food consumption was 1.35 times higher than at the beginning of the treatment $(\mathrm{p}<0.05)$. The Glb-treated group showed a $78.3 \%$ increase in food intake $(\mathrm{p}<0.05)$. In diabetic animals treated with $\mathrm{HH}$ and HR, the food consumption was lower than the consumption in diabetic controls and those treated with Glb. Namely, the groups treated with $\mathrm{HH}$ and HR extracts had significant increase of $45.1 \%$ and $37.7 \%$ respectively.

\section{A}

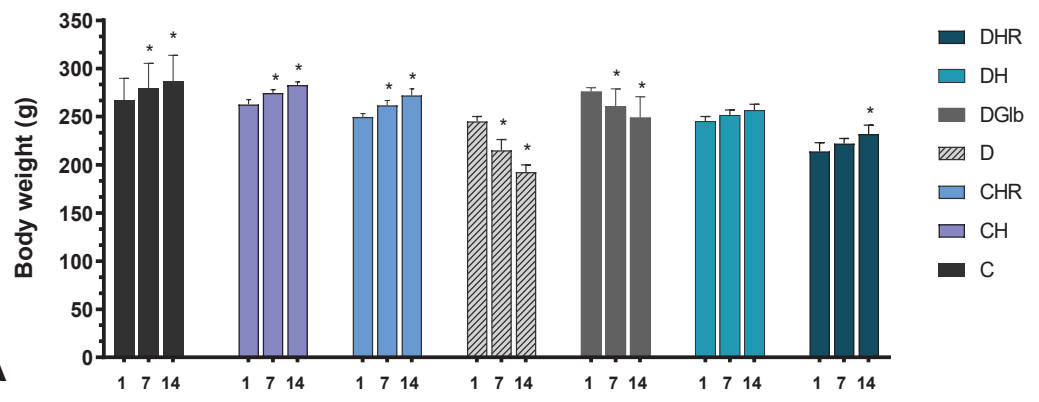

B

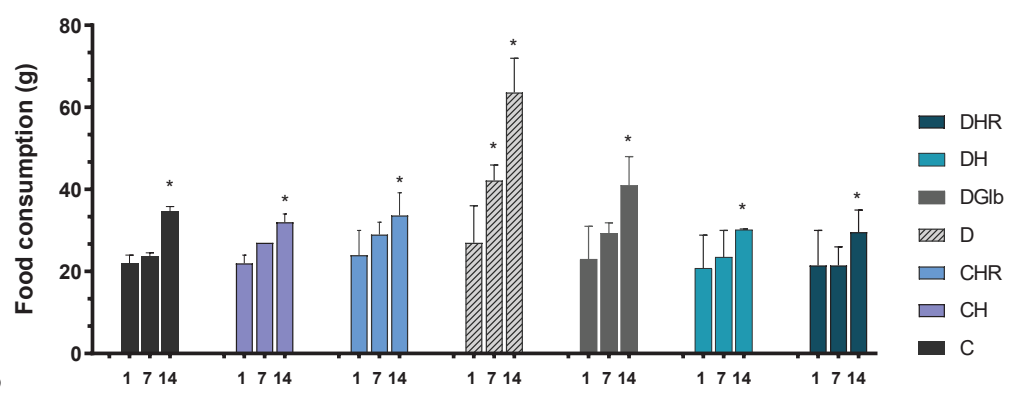

Figure 4. Changes in body weight (A) and food consumption (B) measured on $1^{\text {st }}, 7^{\text {th }}$ and $14^{\text {th }}$ day of the treatment in healthy and diabetic rats with HH and HR extracts. Data are presented as the mean \pm SD. *Significant difference $(\mathrm{p}<0.05)$ compared to day 1 of the treatment
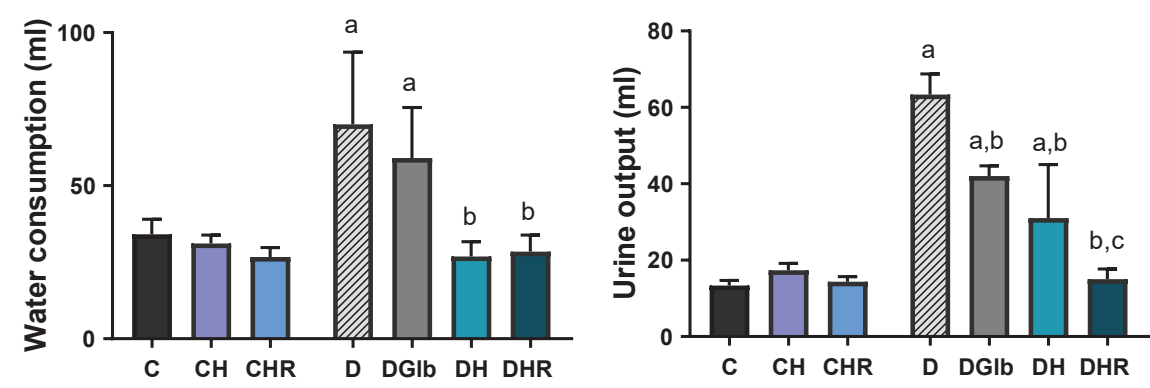

A

B

Figure 5. Changes in water consumption (A) and urine output (B) in healthy and diabetic rats treated with $\mathrm{HH}$ and HR extracts. Data are presented as the mean \pm SD. *Significant differences $(p<0.05)$ : a-compared to $C$; $b$ - compared to D; c-compared to DH 
The effect of the two-week treatment with $\mathrm{HH}$ and $\mathrm{HR}$ extracts on water consumption (A) and urine output (B) in healthy and STZ-diabetic rats is presented on Fig. 5. No significant change in water consumption and urine output was observed in control animals treated with $\mathrm{HH}$ and HR extract (C:CH, C:CHR, ns). On the other hand, experimental diabetes led to a two-fold increase in water consumption and 3.75-fold increase in urine output $(\mathrm{p}<0.05)$. The treatment with Glb did not lead to changes in water consumption (D:DGlb, n.s.), but caused a significant reduction in urine output by $33.6 \%$ compared with diabetic controls (D:DGlb, $\mathrm{p}<0.05)$. The $\mathrm{HH}$ and HR-treatments of diabetic animals caused a significant reduction in water consumption (by $61.6 \%$ and $59.3 \%$, respectively) and urine output (by 51\% and $76.3 \%$, respectively). However, the treatment with HR was more efficient in urine output reduction (DH:DHR, $\mathrm{p}<0.05$ ).

The effect of $\mathrm{HH}$ and HR extracts on the serum lipid profiles in STZ-induced diabetic rats is presented in Table 2. Compared with the normal control group, there was a significant $(p<0.05)$ increase in the CHOL and TAG concentration, in the diabetic control rats, but no significant changes were found in HDL concentration. The treatment of diabetic animals with Glb caused a decrease in serum CHOL (D: DGlb, -25.7\%, p<0.05) and serum TAG (D: DGlb, $-31 \%, \mathrm{p}<0.05$ ), but had no significant effect on HDL concentration (D: DGlb, ns). The treatments of diabetic animals with $\mathrm{HH}$ and HR led to a significant reduction in cholesterol concentration (D: DH, $-29.6 \% \mathrm{p}<0.05$; D: DHR, $-36.9 \%, \mathrm{p}<0.05)$ and TAG (D: DH, $-47.8 \%, \mathrm{p}<0.05$; D: DHR, $-41.5 \%, \mathrm{p}<0.05)$ but showed no significant effect on HDL concentration.

The effect of $\mathrm{HH}$ and HR extracts on the serum enzyme profile in the STZ-treated diabetic rats is presented in Table 3. Treatments of healthy animals with $\mathrm{HH}$ and HR extracts did not cause significant changes in AST and ALT activity. The treatment of healthy animals with $\mathrm{HH}$ caused a significant increase in $\gamma$-GT enzyme activity (C: DH, 20.8\%, $\mathrm{p}<0.05$ ), whereas treatment with HR had no significant effect on this parameter. There was a significant increase in the activity of ALT (C: D, $63.4 \%, \mathrm{p}<0.05)$ and $\gamma-\mathrm{GT}(\mathrm{C}: \mathrm{D}, 64.2 \%, \mathrm{p}<0.05)$, but did not cause any significant changes in AST activity (C: D, ns) in the diabetic control group. The Glb-treatment resulted with non-significant

Table 2. Changes in TAG, CHOL, and HDL in serum of control and diabetic rats treated with $\mathrm{HH}$ and $\mathrm{HR}$ extracts

\begin{tabular}{lccc}
\hline Group & TAG $(\mathbf{m g} / \mathbf{d l})$ & CHOL $(\mathbf{m g} / \mathbf{d l})$ & HDL $(\mathbf{m g} / \mathbf{d l})$ \\
\hline C & $9 \pm 3$ & $33 \pm 3$ & $17 \pm 3$ \\
CH & $11 \pm 2$ & $32 \pm 4$ & $20 \pm 2$ \\
CHR & $8 \pm 1$ & $33 \pm 4$ & $20 \pm 3$ \\
D & $18 \pm 2^{\mathrm{a}}$ & $43 \pm 6^{\mathrm{a}}$ & $20 \pm 2$ \\
DGlb & $12 \pm 2^{\mathrm{b}}$ & $32 \pm 5^{\mathrm{b}}$ & $21 \pm 3$ \\
DH & $9 \pm 1^{\mathrm{b}}$ & $30 \pm 3^{\mathrm{b}}$ & $25 \pm 3$ \\
DHR & $10 \pm 2^{\mathrm{b}}$ & $27 \pm 2^{\mathrm{b}}$ & $24 \pm 4$ \\
\hline
\end{tabular}

Data are presented as the mean \pm SD. Significant differences ( $<<0.05$ ): a-compared to $\mathrm{C}$; b-compared to D

Table 3. Changes in the activity of ALT, AST and $\gamma$-GT in serum of control and diabetic rats treated with HH and HR extracts

\begin{tabular}{lccc}
\hline Group & ALT (U/L) & AST (U/L) & $\gamma$-GT (U/L) \\
\hline C & $59 \pm 5$ & $54 \pm 4$ & $607 \pm 30$ \\
CH & $58 \pm 6$ & $52 \pm 2$ & $733 \pm 45^{\mathrm{a}}$ \\
CHR & $42 \pm 3$ & $53 \pm 3$ & $687 \pm 23$ \\
D & $97 \pm 7^{\mathrm{a}}$ & $44 \pm 6$ & $996 \pm 59^{\mathrm{a}}$ \\
DGlb & $91 \pm 6^{\mathrm{a}}$ & $43 \pm 5$ & $1032 \pm 99^{\mathrm{a}}$ \\
DH & $71 \pm 7^{\mathrm{b}}$ & $52 \pm 4$ & $850 \pm 60^{\mathrm{a}, \mathrm{b}}$ \\
DHR & $74 \pm 6^{\mathrm{b}}$ & $48 \pm 3$ & $785 \pm 48^{\mathrm{a}, \mathrm{b}}$ \\
\hline
\end{tabular}

Data are presented as the mean $\pm \mathrm{SD}$. Significant differences $(\mathrm{p}<0.05)$ : $\mathrm{a}$ - compared to $\mathrm{C}$; b- compared to D 
changes in the activity of the tested enzymes. The treatments of diabetic animals with $\mathrm{HH}$ and HR resulted in a significant reduction in ALT activity (D: DH, $-25.9 \%$ p $<0.05$; D: DHR, $-23.1 \%, \mathrm{p}<0.05$ ) and $\gamma$-GT (D: DH, $-14.6 \%$ p $<0.05$; D: DHR, $-21.2 \%$, $\mathrm{p}<0.05$ ), but did not cause significant changes in AST.

\section{DISCUSSION}

The present study highlighted the hypoglycemic action of the Hairy roots extract in diabetic-induced rats. The single-dose application of $\mathrm{HH}, \mathrm{HR}$ reduced the blood glucose levels of diabetic rats by about $70 \%$ after $24 \mathrm{~h}$. With this reduction, the treatments lead to a state of normoglycemia in the treateddiabetic animals. These effects were comparable with those of Glb, oral hypoglycemic agent of the sulphonylurea group widely used in the treatment of diabetes mellitus (21). Similarly, in the multiple dose study, the difference between the initial and final fasting glucose of $\mathrm{HH}$ and $\mathrm{HR}$ treated diabetic groups revealed a significant reduction in blood glucose. At the end of the experiment (day 14), $\mathrm{HH}$ extract caused a decrease in glycemia by $70.3 \%$ $(\mathrm{p}<0.05)$, while treatment with HR extract by $71.8 \%(p<0.05)$. In this experiment, the effects of both $\mathrm{HH}$ and HR treatments were more emphasized than those of the referent hypoglycemic agent glibenclamide used in this study.

The glucose-lowering properties of $H$. perforatum extracts are already well known $(13,14,15)$ but these are the first findings about the hypoglycemic effect of HR extract in diabetic rats. $H$. perforatum hairy roots are unique model for production of xanthones and previous HPLC analyses clearly demonstrated that $\gamma$-mangostin, mangiferin, and other prenylated and oxygenated xanthones in $H$. perforatum HR cultures are common defense compounds in response to Agrobacterium transformation (17). Several studies of plant extracts rich with $\gamma$-mangostin and prenylated and oxygenated xanthones report strong hypoglycemic effects in STZ diabetic rats (9, $10,11)$. One of the many pharmacological effects of mangiferin is the reduction of plasma glucose in different animal models with diabetes (7) via several unique mechanisms including inhibition of glucosidase (22), which could prevent overloaded carbohydrates from being converted to glucose and absorbed in the intestine.

Some previous results also manifested that $H$. perforatum wild-growing roots showed strong in vitro inhibitory activity against carbohydrate hydrolyzing enzymes $\alpha$-glycosidase and $\alpha$-amylase and thus, could be used for reduction of postprandial hyperglycemia (18). According to Fouotsa et al. (23), the antihyperglycemic properties of xanthones from $H$. perforatum could be related to the structural characteristics of xanthone nucleus (prenylation and hydroxylation pattern) that are essential for effective $\alpha$-glycosidase and $\alpha$-amylase inhibitory activity.

Streptozotocin - induced diabetes is characterized by hyperglycemia, severe changes in metabolic parameters like body weight loss, polydipsia, polyphagia, and polyuria (24). In the present study, we found significantly reduced body weight and increased water and food consumption along with increased urine output in the diabetic rats compared to the non-diabetic rats, indicating that diabetes was effectively induced. In the Glbtreated diabetic group, although less emphasized, we found similar trend of changes as those found in the diabetic control group. Similar results for the effects of Glb on these metabolic parameters in STZ-diabetic rats have been reported by Moodley et al. (25). Unlike the Glb treatment, both $\mathrm{HH}$ and HR extracts improved body weight, decreased food consumption and significantly reduced water intake and urine output in diabetic rats, which might result from improved glycemic control.

Abnormal lipid metabolism, leading to accumulation of plasma LDL, VLDL, and total cholesterol as well as decreased HDL-cholesterol, is commonly associated with diabetes mellitus (26). In the STZ diabetic group we found an increase in the level of CHOL and TAG, but no significant changes in HDL concentration when compared to the normal control group (Table 2). The treatments of diabetic animals with $\mathrm{HH}$ and $\mathrm{HR}$ led to a significant reduction in cholesterol and TAG, but did not alter the HDL concentration. It is known that $H$. perforatum extract can modulate blood lipid abnormalities at the experimental level $(12,13$, 15). Several of the xanthones which are present in the HR extract can modulate the lipid metabolism (mangiferin, mangosteen, and xanthones with 1,3,5,6-tetrahydroxyoxanthantone structure) (18, 19). Namely, mangiferin normalizes the levels of cholesterol, triglycerides, free fatty acids, improves the balance between LDL and HDL in diabetic animals $(27,28,29)$, and improves the lipid profile in humans (30). Alpha mangosteen applied in nanoconcentrations for only one week causes a decrease in the concentration of cholesterol and LDL in diabetic mice (31). 
Finally, we estimated the considered serum enzyme profile like biomarkers of hepatocellular damage. Elevated levels of liver transaminases, alanine aminotransferase (ALT), aspartate aminotransferase (AST), and $\gamma$-glutamyl transferase $(\gamma-\mathrm{GT})$ are associated with fatty liver disease and hyperglycemia in diabetes $(32,33)$. The treatment of diabetic rats with both $\mathrm{HH}$ and HR significantly reduced ALT and $\gamma$-GT levels (Table 3), suggesting that they can ameliorate STZ-induced hepatocyte injury in diabetic rats. Our results are consistent with those of Mohammad et al. (15) which in addition to the effects on lipid metabolism have shown that $H$. perforatum extracts normalize the activities of AST and ALT in diabetic animals. On the other hand, xanthones are known to possess a hepatoprotective effect on diabetic rats $(34,35)$.

\section{CONCLUSION}

In conclusion, Hypericum perforatum hairy roots extract exhibited potent antihyperglycemic effect in STZ-induced diabetic rats without inducing hypoglycemic state. HR extracts manifested regulation of metabolic parameters, as well as serum lipid and enzyme profile in multiple dose treatment of diabetic rats. These multiple advantageous properties of the HR extract could be of greater therapeutic benefit in the management of diabetes mellitus. Still, further studies are necessary to evaluate the effects of HR-extracts on insulin secretion and the carbohydrate metabolism.

\section{CONFLICT OF INTEREST}

The authors declare that they have no potential conflict of interest with respect to the authorship and/or publication of this article.

\section{ACKNOWLEDGMENTS}

This research was supported by the Institute of Biology, Faculty of Natural Sciences and Mathematics in Skopje.

\section{AUTHORS' CONTRIBUTION}

ER, BM and SDK conceived and designed the study, supervised the experiments and data analysis, interpreted the results, performed a major part of the experiments and wrote the manuscript. OT and SGS prepared the plant extracts, participated in designing the study, and contributed to finalizing the manuscript.

\section{REFERENCES}

1. May, L.D., Lefkowitch, J.H., Kram, M.T., Rubin, D.E. (2002). Mixed hepatocellular-cholestatic liver injury after pioglitazone therapy. Ann Intern Med. 136(6): 449-452.

https://doi.org/10.7326/0003-4819-136-6-200203190-00008 PMid:11900497

2. Sun, J.E., Ao, Z.H., Lu, Z.M., Xu, H.Y., Zhang, X.M., Dou, W.F., Xu, Z.H. (2008). Antihyperglycemic and antilipidperoxidative effects of dry matter of culture broth of Inonotus obliquus in submerged culture on normal and alloxan-diabetes mice. J Ethnopharmacol. 118(1): 7-13.

https://doi.org/10.1016/j.jep.2008.02.030

PMid:18434051

3. Li, W., Zheng, L., Sheng, C., Cheng, X., Qing, L., $\mathrm{Qu}$, S. (2011). Systematic review on the treatment of pentoxifylline in patients with non-alcoholic fatty liver disease. Lipids Health Dis. 10, 49.

https://doi.org/10.1186/1476-511X-10-49

PMid:21477300 PMCid:PMC3088890

4. Nahrstedt, A., Butterweck, V. (2010). Lessons learned from herbal medicinal products: the example of St. John's wort. J Nat Prod. 73(5): 1015-1021.

https://doi.org/10.1021/np1000329

PMid:20408551

5. Velingkar, V.S., Gupta, G.L., Hegde, N.B. (2017). A current update on phytochemistry, pharmacology and herb-drug interactions of Hypericum perforatum. Phytochem Rev. 16(4): 725-744.

https://doi.org/10.1007/s11101-017-9503-7

6. Asgarpanah, J. (2012). Phytochemistry, pharmacology and medicinal properties of Hypericum perforatum L. Afr J Pharmacy and Pharmacol. 6(19): 1387-1394. https://doi.org/10.5897/AJPP12.248

7. Fomenko, E.V., Chi, Y. (2016). Mangiferin modulation of metabolism and metabolic syndrome. Biofactors 42(5): 492-503.

https://doi.org/10.1002/biof.1309

PMid:27534809 PMCid:PMC5077701

8. Apontes, P., Liu, Z., Su, K., Benard, O., Youn, D.Y., Li, X., Li, W., et al. (2014). Mangiferin stimulates carbohydrate oxidation and protects against metabolic disorders induced by high-fat diets. Diabetes 63(11): 3626-3636.

https://doi.org/10.2337/db14-0006

PMid:24848064 PMCid:PMC4207399

9. Ibrahim, S.R., Abdallah, H.M., El-Halawany, A.M., Nafady, A.M., Mohamed, G.A. (2019). Mangostanaxanthone VIII, a new xanthone from Garcinia mangostana and its cytotoxic activity. Nat Prod Res. 33(2): 258-265.

https://doi.org/10.1080/14786419.2018.1446012 PMid:29513040 
10. Ratwita, W., Sukandar, E.Y., Adnyana, I.K., Kurniati, N.F. (2019). Alpha mangostin and Xanthone activity on fasting blood glucose, insulin and langerhans Islet of langerhans in Alloxan induced diabetic mice. Pharmacogn J. 11(1): 64-68. https://doi.org/10.5530/pj.2019.1.12

11. Malik, A., Ardalani, H., Anam, S., McNair, L.M., Kromphardt, K.J., Frandsen, R.J.N., Franzyk, H., et al. (2020). Antidiabetic xanthones with $\alpha$-glucosidase inhibitory activities from an endophytic Penicillium canescens. Fitoterapia 142, 104522. https://doi.org/10.1016/j.fitote.2020.104522 PMid:32088281

12. Husain, G.M., Singh, P.N., Kumar, V. (2009). Beneficial effects of a standardized Hypericum perforatum extract in rats with experimentally induced hyperglycemia. Drug Discov Ther. 3(5): 215-220.

13. Arokiyaraj, S., Balamurugan, R., Augustian, P. (2011). Antihyperglycemic effect of Hypericum perforatum ethyl acetate extract on streptozotocin-induced diabetic rats. Asian Pac J Trop Biomed. 1(5): 386-390. https://doi.org/10.1016/S2221-1691(11)60085-3

14. Can, Ö.D., Öztürk, Y., Öztürk, N., Sagratini, G., Ricciutelli, M., Vittori, S., Maggi, F. (2011). Effects of treatment with St. John's Wort on blood glucose levels and pain perceptions of streptozotocindiabetic rats. Fitoterapia 82(4): 576-584.

https://doi.org/10.1016/j.fitote.2011.01.008 PMid:21262331

15. Moghadam, M.G., Ansari, I., Roghani, M., Ghanem, A., Mehdizade, N. (2017). The effect of oral administration of Hypericum perforatum on serum glucose and lipids, hepatic enzymes and lipid peroxidation in streptozotocin-induced diabetic rats. Galen Medical J. 6(4): 319-329.

16. Tocci, N., Gaid, M., Kaftan, F., Belkheir, A.K., Belhadj, I., Liu, B., Svatoš, A., et al. (2018). Exodermis and endodermis are the sites of xanthone biosynthesis in Hypericum perforatum roots. New Phytologist 217(3): 1099-1112.

https://doi.org/10.1111/nph.14929

PMid:29210088

17. Tusevski, O., Krstikj, M., Petreska Stanoeva, J., Stefova, M., Gadzovska Simic, S. (2019). Phenolic compounds composition of Hypericum perforatum L. wild-growing plants from the Republic of Macedonia. Agric Conspec Sci. 84(1): 67-75.

18. Tusevski, O., Petreska Stanoeva, J., Stefova, M., Kungulovski, Dz., Atanasovsa Pancevska, N., Sekulovski, N., Panov, S., Gadzovska Simic, S. (2013). Hairy roots of Hypericum perforatum L.: a promising system for xanthone production. Cent Eur J Biol. 8(10): 1010-1022.

https://doi.org/10.2478/s11535-013-0224-7
19. Tusevski, O., Vinterhalter, B., Milošević, D.K., Soković, M., Ćirić, A., Vinterhalter, D., Korać, S.Z., et al. (2017). Production of phenolic compounds, antioxidant and antimicrobial activities in hairy root and shoot cultures of Hypericum perforatum L. PCTOC 128(3): 589-605.

https://doi.org/10.1007/s11240-016-1136-9

20. Gadzovska, S., Maury, S., Ounnar, S., Righezza, M., Kascakova, S., Refregiers, M., Spasenoski, M., et al. (2005). Identification and quantification of hypericin and pseudohypericin in different Hypericum perforatum L. in vitro cultures. Plant Physiol Biochem. 43(6): 591-601.

https://doi.org/10.1016/j.plaphy.2005.05.005

PMid:15979315

21. Idries, A.M., Ahmed, M.E., Mudawi, M.E., Ibrahim, K.E. (2012). Interchangeability and comparative effectiveness between micronized and non-micronized products of glibenclamide tablets. Sudan JMS. 7(3): 153-159.

22. Li, Y., Peng, G., Li, Q., Wen, S., Huang, T.H.W., Roufogalis, B.D., Yamahara, J. (2004). Salacia oblonga improves cardiac fibrosis and inhibits postprandial hyperglycemia in obese Zucker rats. Life Sci. 75(14): 1735-1746.

https://doi.org/10.1016/j.1fs.2004.04.013

PMid:15268973

23. Fouotsa, H., Lannang, A.M., Mbazoa, C.D., Rasheed, S., Marasini, B.P., Ali, Z., Devkota, K.P., et al. (2012). Xanthones inhibitors of $\alpha$-glucosidase and glycation from Garcinia nobilis. Phytochem Lett. 5(2): 236-239.

https://doi.org/10.1016/j.phytol.2012.01.002

24. Szkudelski, T., Szkudelska, K. (2002). Streptozotocin induces lipolysis in rat adipocytes in vitro. Physiol Res. 51(3): 255-259.

25. Moodley, K., Joseph, K., Naidoo, Y., Islam, S., Mackraj, I. (2015). Antioxidant, antidiabetic and hypolipidemic effects of Tulbaghia violacea Harv. (wild garlic) rhizome methanolic extract in a diabetic rat model. BMC Complement Altern Med. 15,408 .

https://doi.org/10.1186/s12906-015-0932-9

PMid:26577219 PMCid:PMC4647322

26. Kondeti, V.K., Badri, K.R., Maddirala, D.R., Thur, S.K.M., Fatima, S.S., Kasetti, R.B., Rao, C.A. (2010). Effect of Pterocarpus santalinus bark, on blood glucose, serum lipids, plasma insulin and hepatic carbohydrate metabolic enzymes in streptozotocin-induced diabetic rats. Food Chem Toxicol. 48(5): 1281-1287.

https://doi.org/10.1016/j.fct.2010.02.023

PMid:20178824 
27. Lim, J., Liu, Z., Apontes, P., Feng, D., Pessin, J.E., Sauve, A.A., Angeletti, R.H., Chi, Y. (2014). Dual mode action of mangiferin in mouse liver under high fat diet. PloS One 9(6): e100170.

https://doi.org/10.1371/journal.pone.0100170

PMCid:PMC4061128

28. Xing, X., Li, D., Chen, D., Zhou, L., Chonan, R., Yamahara, J., Wang, J., Li, Y. (2014). Mangiferin treatment inhibits hepatic expression of acylcoenzyme A: diacylglycerol acyltransferase-2 in fructose-fed spontaneously hypertensive rats: a link to amelioration of fatty liver. Toxicol Appl Pharmacol. 280(2): 207-215.

https://doi.org/10.1016/j.taap.2014.08.001

PMid:25123789

29. Zhou, G.Y., Yi, Y.X., Jin, L.X., Lin, W., Fang, P.P., Lin, X.Z., Zheng, L., Pan, C.W. (2016). The protective effect of juglanin on fructose-induced hepatitis by inhibiting inflammation and apoptosis through TLR4 and JAK2/STAT3 signaling pathways in fructose-fed rats. Biomed Pharmacother. 81, 318-328.

https://doi.org/10.1016/j.biopha.2016.04.013

PMid:27261609

30. Na, L., Zhang, Q., Jiang, S., Du, S., Zhang, W., Li, Y., Changhao, S., Niu, Y. (2015). Mangiferin supplementation improves serum lipid profiles in overweight patients with hyperlipidemia: a doubleblind randomized controlled trial. Sci Rep. 5, 10344. https://doi.org/10.1038/srep10344 PMid:25989216 PMCid:PMC4437311

31. Karim, N., Tangpong, J. (2018). Biological properties in relation to health promotion effects of Garcinia mangostana (queen of fruit): A short report. J Health Res. 32(5): 364-370. https://doi.org/10.1108/JHR-08-2018-043
32. Juárez-Rojop, I.E., Díaz-Zagoya, J.C., Ble-Castillo, J.L., Miranda-Osorio, P.H., Castell-Rodríguez, A.E., Tovilla-Zárate, Rodríguez-Hernández, A., et al. (2012). Hypoglycemic effect of Carica papaya leaves in streptozotocin-induced diabetic rats. BMC Complement Altern Med. 12, 236.

https://doi.org/10.1186/1472-6882-12-236

PMid:23190471 PMCid:PMC3551835

33. Ghorbani, Z., Hekmatdoost, A., Mirmiran, P. (2014). Anti-hyperglycemic and insulin sensitizer effects of turmeric and its principle constituent curcumin. Int J Endocrinol Metab. 12(4): e18081. https://doi.org/10.5812/ijem.18081 PMid:25745485 PMCid:PMC4338652

34. Mahendran, G., Manoj, M., Murugesh, E., Kumar, R.S., Shanmughavel, P., Prasad, K.R., Bai, V.N. (2014). In vivo anti-diabetic, antioxidant and molecular docking studies of 1, 2, 8-trihydroxy-6-methoxy xanthone and 1, 2-dihydroxy-6-methoxyxanthone8-O- $\beta$-D-xylopyranosyl isolated from Swertia corymbosa. Phytomedicine 21(11): 1237-1248. https://doi.org/10.1016/j.phymed.2014.06.011 PMid:25172785

35. As'ari, H., Mahartini, D.M. (2016). The effect of administering mangosteen rind extract (Garnicia mangostana 1) compared with glimepiride to the blood sugar levels of white male rat (Rattus norwegicus 1) induced by streptozotocin. Folia Medica Indonesiana 52(4): 241-245. https://doi.org/10.20473/fmi.v52i4.5469

Please cite this article as: Rafailovska E., Tushevski O., Gadzovska-Simic S., Dinevska-Kjovkarovska S., Miova B. Hypericum perforatum L. hairy root extracts - regulation of glycemic, metabolic and serum enzyme and lipid profile in STZ - induced diabetic rats. Mac Vet Rev 2022; 45 (1): 5-15. https://doi.org/10.2478/macvetrev-2021-0027 